\title{
Significance of Thrombocytosis in Clinicopathologic Characteristics and Prognosis of Gastric Cancer
}

\author{
Fang-Xuan Li, Li-Juan Wei, Huan Zhang, Shi-Xia Li, Jun-Tian Liu*
}

\begin{abstract}
Purpose: We aimed to study the relationship between thrombocytosis and clinical features of gastric cancerfocussing on platelet counts and gastric cancer progression through different TNM stages. Methods: According to the normal range of platelet count in our institution, 1,596 patients were divided to two groups: a thrombocytosis group $(120$ patients, $>400 \times 1000 / \mu \mathrm{L})$ and a control group $(1,476$ patients, $\leq 400 \times 1000 / \mu \mathrm{L})$. Results: The incidence of thrombocytosis was $7.5 \%$. Higher platelet counts were observed in patients with older age, larger tumor size, deeper invasion, lymph node metastasis, distant metastasis and advanced TNM stage. In multivariate logistic regression, tumor size, depth of tumor invasion, lymph node metastasis and TNM stage were independent risk factors for thrombocytosis of gastric cancer patients. On prognostic analysis, age, tumor size, tumor location, histologic type, depth of tumor invasion, lymph node metastasis, distant metastasis and TNM stage and platelet count were important factors. Tumor size, invasion depth, lymph node metastasis, TNM stage and the platelet count were independent prognostic factors. Conclusion: Thrombocytosis is associated with clinical features of gastric cancer patients and correlates with a poor prognosis.
\end{abstract}

Keywords: Gastric cancer - thrombocytosis - clinical factors - prognosis

Asian Pac J Cancer Prev, 15 (16), 6511-6517

\section{Introduction}

Clinical abnormalities of coagulation may be detected as the first symptom of malignancy. One-third of cancer patients have elevation of blood platelet count at the time of diagnosis and before treatment (Naschitz et al. 1996), and the thrombocytosis is reported to be present in $10 \%$ to $57 \%$ of various neoplasm patients (Sierko and Wojtukiewicz 2004). Previous studies have showed that thrombocytosis is associated with later stage, lymphatic and blood-borne metastasis and higher risk of recurrence in many cancers (Gao et al., 2013; Sasaki et al., 2012; Unal et al., 2013). It was also suggested that patients with thrombocytosis usually inclined to poorer prognoses in ovarian cancer (Lee et al., 2011), renal cell carcinoma (Cho et al., 2011), colorectal cancer and gastric cancer (Hwang et al., 2012). Although, several mechanisms of platelet action in facilitating cancer progression and metastasis have been supposed, exact pathophysiological mechanisms of it have not been completely elaborated. Based on the pivotal role of platelet and thrombocytosis in developing, metastasis and prognosis of cancers, several studies have suggested thrombocytosis as a therapeutic targets in cancer treatments, especially against to the metastatic cancer cells. Several platelet aggregation inhibitors have been reported to retard tumor metastasis in certain animal models and some clinical trials (Choe et al., 2010; Kuderer et al., 2007; Phillips et al., 2011).

Gastric cancer is the fourth most common cancer in the world and accounts for nearly $8.6 \%$ of all new cancers. It remains be a leading cause of cancer-related death which causes $12 \%$ of all cancer-related deaths each year (Jemal et al., 2011; Li et al., 2012). Also in gastric cancer, the higher platelets counts could be detected at initial diagnosis, the incidence of thrombocytosis was ranged from 6.4\%-20.4\% in gastric cancer (Ikeda et al., 2002). The prognostic significance of thrombocytosis was previously reported by some literatures. However, these studies should be complemented because of their more or less shortcomings. Aliustaoglu et al. (2010) and Ikeda et al. (2002) analyzed a relatively small number of patients while Heras et al. (2010) analyzed only a short-term mortality rate without delineating the prevalence of thrombocytosis in gastric cancer patients. Based on a larger group, Hwang et al. (2012) focused on the association between thrombocytosis and hematogenous recurrence. However, undetailed TNM staging and group division in statistic analysis reduced the study's reference meanings in the thrombocytosis research. In this study, we aimed to study the relationship with thrombocytosis and the clinicopathology characters of gastric cancer based on retrospective analysis of 1596 gastric cancer patients. Furthermore, we can investigate the association between platelet counts and gastric cancer progression upon different TNM stages. 


\section{Materials and Methods}

The eligibility criteria for this study included: (1) Histologically confirmed gastric carcinoma at the Gastric Cancer Surgery Department, Tianjin Medical University Cancer Institution and Hospital, between January 1997 and December 2000. (2) Patients who had complete clinical and follow-up data. (3) Patients received the surgery and chemotherapy according to the rules of the Japanese Research Society for Gastric Cancer(JRSGC).

The exclusion criteria included: (1) Patients with other-organ malignancy, severe liver cirrhosis, recent infectious disorder or inflammatory disease. (2) Gastric cancer patients at I-III stage who did not received a curative resection ( $\mathrm{R} 0$ resection) with lymphadenectomy (dissected lymph nodes were more than 15).

\section{Patients}

Based on eligibility and exclusion criteria given above, there were 1596 patients enrolled in our study. In these patients, 1127 patients were males and 469 patients were females. Their ages ranged from 25 to 89 years with a median age of 60 years. Medical records were reviewed to extract the patients' data, including age at the time of diagnosis $(<60$ or $\geq 60)$, sex (male or female), tumor location(upper $\&$ diffuse or middle \&lower), size of tumor $(\leq 5 \mathrm{~cm}$ or $>5 \mathrm{~cm})$, histological type (differentiated type or undifferentiated type), depth of tumor invasion (T1, T2, T3, T4a or T4b), lymph node metastasis (N0, $\mathrm{N} 1, \mathrm{~N} 2$ or N3). All histopathological data were analyzed and determined according to the Union for international cancer control (UICC) TNM classification (7th edition) (Greene and Sobin 2009). In all patients, 1510 patients received radical resection, meanwhile 1462 patients received chemotherapy.

The current study was conducted in compliance with the Declaration of Helsinki for the use of patients' data and protection of their confidentiality.

\section{Platelet count and thrombocytosis}

The pretreatment platelet count was recorded according to the last preoperative complete blood count performed either at admission for surgery or at outpatient clinic within 2 weeks before surgery. Platelet count $>400 \times 1000 / \mu \mathrm{L}$ was defined as thrombocytosis(Ikeda et al., 2002).

\section{Follow-up plan}

Follow-up were conducted through outpatient department visiting. All of the patients were followed every 3 months for the first year, every 6 months for second year, then every year until death.

\section{Statistic analysis}

Independent sample $t$ test was used in comparison of continuous variables. The chi-squared and Fisher exact tests were applied in categorical variable for univariate analysis of potential factors for thrombocytosis. Logistic regression was used for the multivariate analysis of relative factors of thrombocytosis. Overall survival was estimated by the Kaplan-Meier method and the Log-rank test was used to determine univariate significance. The Cox regression was applied in multivariate prognosis analysis. Significance was defined as $p<0.05$ (two sides). The statistical analysis was performed using the statistical analysis program package SPSS 17.0.

Table 1. The Association between Platelet Count and Clinicopathological Factors

\begin{tabular}{|c|c|c|c|c|c|}
\hline Factors & & $\mathrm{n}$ & $\begin{array}{l}\text { Platelet count } \\
(\times 1000 / \mu \mathrm{L})\end{array}$ & $\mathrm{t}$ & $P$ \\
\hline \multirow[t]{2}{*}{ Sex } & Male & 1127 & $250.49 \pm 90.20$ & 1.924 & 0.054 \\
\hline & Female & 469 & $259.86 \pm 80.70$ & & \\
\hline \multirow[t]{2}{*}{ Age } & $<60$ & 790 & $246.12 \pm 90.01$ & 3.241 & 0.001 \\
\hline & $\geq 60$ & 806 & $260.44 \pm 86.39$ & & \\
\hline \multirow[t]{2}{*}{ Tumor size } & $\leq 5 \mathrm{~cm}$ & 674 & $232.02 \pm 71.01$ & 8.367 & $<0.001$ \\
\hline & $>5 \mathrm{~cm}$ & 922 & $268.74 \pm 96.44$ & & \\
\hline \multirow[t]{2}{*}{ tumor location } & Upper \& Diffuse & 759 & $251.35 \pm 87.08$ & 0.808 & 0.419 \\
\hline & Middle \& Lower & 837 & $254.94 \pm 87.74$ & & \\
\hline \multirow[t]{2}{*}{ Histologic type } & Differentiated type & 861 & $253.17 \pm 88.26$ & 0.03 & 0.976 \\
\hline & Undifferentiated type & 735 & $253.30 \pm 88.79$ & & \\
\hline \multirow[t]{5}{*}{ Depth of tumor invasion } & $\mathrm{T} 1$ & 43 & $206.09 \pm 57.49$ & 7.143 & $<0.001$ \\
\hline & $\mathrm{T} 2$ & 156 & $231.09 \pm 65.81$ & & \\
\hline & T3 & 103 & $266.71 \pm 108.59$ & & \\
\hline & $\mathrm{T} 4$ & 1167 & $255.22 \pm 88.23$ & & \\
\hline & $\mathrm{T} 4 \mathrm{~b}$ & 127 & $267.24 \pm 96.56$ & & \\
\hline \multirow[t]{4}{*}{ Lymph node metastasis } & N0 & 560 & $244.91 \pm 83.76$ & 3.424 & 0.017 \\
\hline & N1 & 317 & $252.37 \pm 87.82$ & & \\
\hline & $\mathrm{N} 2$ & 345 & $256.83 \pm 87.97$ & & \\
\hline & N3 & 374 & $263.11 \pm 88.47$ & & \\
\hline \multirow[t]{2}{*}{ Distant metastasis } & M0 & 1508 & $251.95 \pm 87.73$ & 2.688 & 0.01 \\
\hline & M1 & 88 & $299.48 \pm 113.64$ & & \\
\hline \multirow[t]{4}{*}{ TNM stage } & I & 136 & $222.01 \pm 63.19$ & 9.608 & $<0.001$ \\
\hline & II & 465 & $247.23 \pm 83.45$ & & \\
\hline & III & 907 & $258.81 \pm 91.98$ & & \\
\hline & IV & 88 & $257.72 \pm 97.54$ & & \\
\hline
\end{tabular}




\section{Results}

\section{Patient characteristics}

In the present study, the mean platelet count was $253.23 \pm 88.47 \times 1000 / \mu \mathrm{L}$, ranged from 51 to $678 \times 1000 / \mu \mathrm{L}$. All patients were divided to two groups: thrombocytosis group (120 patients, $>400 \times 1000 / \mu \mathrm{L})$ and control group $(1476$ patients, $\leq 400 \times 1000 / \mu \mathrm{L})$. The incidence of thrombocytosis in our study was $7.5 \%$.

The higher platelet count were observed in patients with older age $(p=0.001)$, larger tumor size $(p<0.001)$, deeper tumor invasion $(p<0.001)$, lymph node metastasis $(p=0.017)$, distant metastasis $(p=0.010)$, and advanced TNM stage $(p<0.001)$, shown in Table 1 . The association between the maximum tumor diameter, depth of tumor invasion, lymph node metastasis, TNM stage and the platelet count were showed in Figures 1-4.

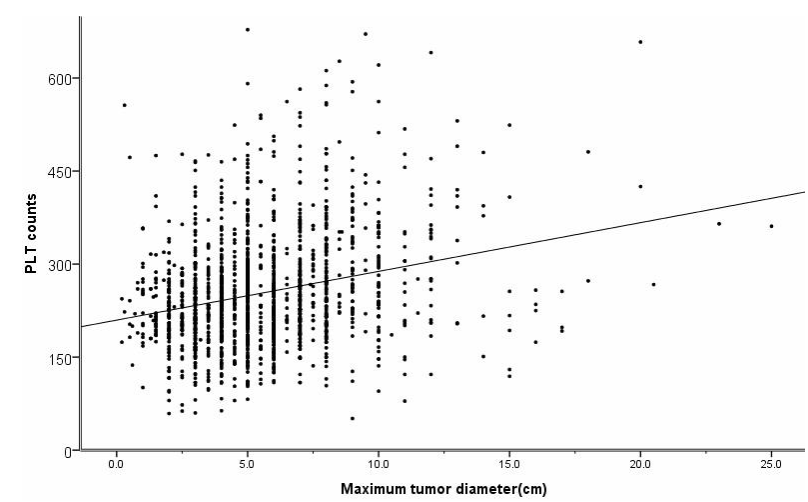

Figure 1. The Association between Platelet Count and Maximum Tumor Diameter

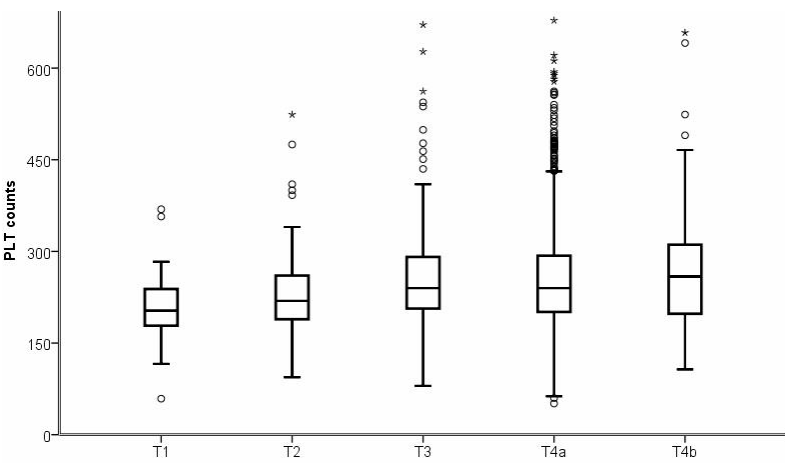

Figure 2. The Association between Platelet Count and Depth of Invasion

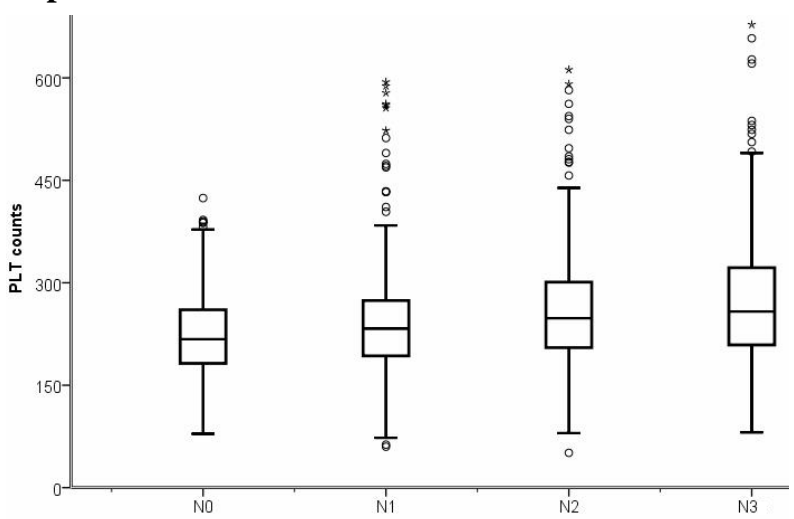

Figure 3. The Association between Platelet Count and Lymph Node Metastasis
DOI:http://dx.doi.org/10.7314/APJCP.2014.15.16.6511

Sigificance of Thrombocytosis in Gastric Cancer Prognosis

The association between thrombocytosis and clinicopathological factors

Table 2 showed the results of univariate analysis of the association between thrombocytosis and clinicopathological variables. The significant correlation between the thrombocytosis and clinicopathological features was demonstrated in tumor size, tumor location, depth of tumor invasion, lymph node metastasis, distant metastasis and TNM stage (All P values were $<0.05$ ). The thrombocytosis was observed more frequently in patients with larger tumor size $(p<0.001)$, location at middle or lower third stomach $(p=0.013)$, deeper tumor invasion $(p=0.012)$, later $\mathrm{N}$ stage $(p=0.046)$, distant metastasis $(p=0.048)$ and advanced TNM stage $(p<0.001)$.

These significant features were enrolled in multivariate logistic regression, we detected that tumor size $(p<0.001)$, depth of tumor invasion ( $p=0.045)$, lymph node metastasis $(p=0.031)$ and TNM stage $(p=0.023)$ were independent risk factors for thrombocytosis of gastric cancer patients.

\section{Prognostic analysis of gastric cancer patients}

We investigated the prognostic factors for gastric patients by Kaplan-merier and Log-rank test. It was demonstrated that beside age $(p=0.001)$, tumor size $(p<0.001)$, tumor location $(p<0.001)$, histologic type $(p<0.001)$, depth of tumor invasion $(p<0.001)$, lymph node metastasis $(p<0.001)$, distant metastasis $(p<0.001)$ and TNM stage $(p<0.001)$, the platelet count $(p=0.006$, Figure 1) was also an important prognostic factor for prognosis of gastric cancer.

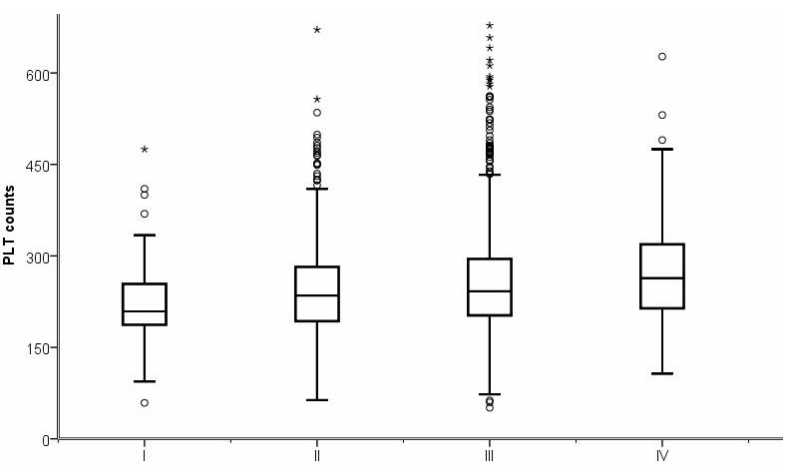

Figure 4. The Association between Platelet Count and TNM Stage

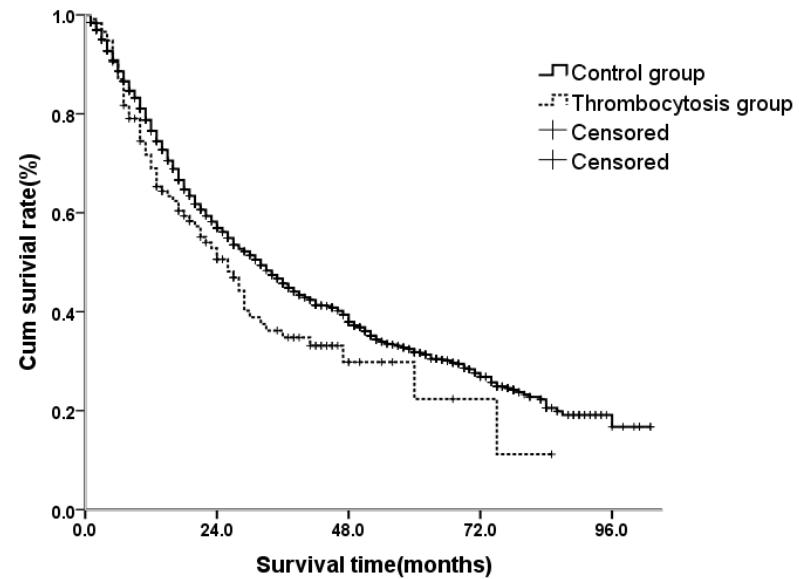

Figure 5. The Impact of Platelet Count on Prognosis of Gastric Cancers 
Fang-Xuan Li et al

Table 2. Univariate and Multivariate Analysis of The Association between Clinicopathological Factors and Thrombocytosis of Gastric Cancers

\begin{tabular}{|c|c|c|c|c|c|c|c|c|}
\hline \multirow[b]{2}{*}{ Factors } & \multirow[b]{2}{*}{$\mathrm{n}$} & \multicolumn{4}{|c|}{ Univariate analysis } & \multicolumn{3}{|c|}{ Multivariate logistic analysis } \\
\hline & & $\begin{array}{l}\text { Control group } \\
\quad(n=1476)\end{array}$ & $\begin{array}{c}\text { Thrombocytosis } \\
\text { group }(n=120)\end{array}$ & $\mathrm{t}$ & $P$ & HR & $\mathrm{x}^{2}$ & $P$ \\
\hline Sex & & & & 0.131 & 0.717 & & & \\
\hline Male & 1127 & 1044 (92.6) & $83(8.0)$ & & & & & \\
\hline Female & 469 & $432(74.8)$ & $37(7.9)$ & & & & & \\
\hline Age & & & & 0.448 & 0.508 & & & \\
\hline$<60$ & 791 & $728(92.0)$ & $63(8.0)$ & & & & & \\
\hline$\geq 60$ & 805 & 748 (92.9) & $57(7.1)$ & & & & & \\
\hline Tumor size & & & & 26.285 & $<0.001$ & & 21.159 & $<0.001$ \\
\hline$\leq 5 \mathrm{~cm}$ & 674 & $650(96.4)$ & $24(3.6)$ & & & $0.370(0.200-0.523)$ & & \\
\hline$>5 \mathrm{~cm}$ & 922 & $826(89.6)$ & $96(10.4)$ & & & 1 & & \\
\hline Tumor location & & & & 6.17 & 0.013 & & 3.052 & 0.081 \\
\hline Upper \& Diffuse & 759 & $715(94.2)$ & $44(5.8)$ & & & $0.790(0.606-1.029)$ & & \\
\hline Middle \& Lower & 837 & $761(90.9)$ & $76(9.1)$ & & & 1 & & \\
\hline Histologic type & & & & 3.112 & 0.078 & & & \\
\hline Differentiated type & 861 & 787 (91.4) & $74(8.6)$ & & & & & \\
\hline Undifferentiated type & 735 & $689(93.7)$ & $46(6.3)$ & & & & & \\
\hline Depth of tumor invasion & & & & 12.895 & 0.012 & & 7.951 & 0.045 \\
\hline $\mathrm{T} 1$ & 43 & $43(100.0)$ & $0(0.0)$ & & & $1.364(1.063-1.751)$ & 5.952 & 0.015 \\
\hline $\mathrm{T} 2$ & 156 & $151(96.8)$ & $5(3.2)$ & & & $1.509(0.540-4.217)$ & 0.616 & 0.433 \\
\hline $\mathrm{T} 3$ & 103 & $90(87.4)$ & $13(12.6)$ & & & $1.554(0.772-3.129)$ & 1.525 & 0.217 \\
\hline $\mathrm{T} 4 \mathrm{a}$ & 1167 & $1078(92.4)$ & $89(7.6)$ & & & $1.234(0.772-1.973)$ & 0.775 & 0.379 \\
\hline $\mathrm{T} 4 \mathrm{~b}$ & 127 & $114(89.8)$ & $13(10.2)$ & & & 1 & & \\
\hline lymph node metastasis & & & & 7.445 & 0.046 & & 8.902 & 0.031 \\
\hline No & 560 & $525(93.8)$ & $35(6.3)$ & & & $2.740(1.275-5.888)$ & 6.668 & 0.01 \\
\hline N1 & 317 & $296(93.4)$ & $21(6.6)$ & & & $0.913(0.628-1.327)$ & 0.228 & 0.633 \\
\hline N2 & 345 & $321(93.0)$ & $24(7.0)$ & & & $0.895(0.630-1.273)$ & 0.38 & 0.538 \\
\hline N3 & 374 & $334(89.3)$ & $40(10.7)$ & & & 1 & & \\
\hline Distant metastasis & & & & 3.723 & 0.048 & & 0.606 & 0.436 \\
\hline M0 & 1508 & $1399(92.8)$ & $109(7.2)$ & & & $0.504(0.090-2.813)$ & & \\
\hline M1 & 88 & $77(87.5)$ & $11(12.5)$ & & & 1 & & \\
\hline TNM stage & & & & 19.993 & $<0.001$ & & 9.544 & 0.023 \\
\hline I & 136 & $133(97.8)$ & $3(2.2)$ & & & $0.142(0.031-0.641)$ & 6.433 & 0.011 \\
\hline II & 465 & $434(93.3)$ & $31(6.7)$ & & & $0.257(0.104-0.638)$ & 8.592 & 0.003 \\
\hline III & 907 & 832 (91.7) & $75(8.3)$ & & & $0.797(0.483-1.316)$ & 0.788 & 0.375 \\
\hline IV & 88 & $77(87.5)$ & $11(12.5)$ & & & 1 & & \\
\hline
\end{tabular}

Table 3. Univariate and Multivariate Prognostic Analysis of Gastric Cancers

\begin{tabular}{|c|c|c|c|c|c|c|c|c|}
\hline \multirow[t]{2}{*}{ Factors } & \multirow[t]{2}{*}{$\mathrm{n}$} & \multicolumn{4}{|c|}{ Univariate analysis } & \multicolumn{3}{|c|}{ Multivariate analysis } \\
\hline & & 3-YSR & 5-YSR & $x^{2}$ & $P$ & HR & $x^{2}$ & $P$ \\
\hline Sex & & & & 1.758 & 0.185 & & & \\
\hline Male & 1127 & $45.40 \%$ & $31.90 \%$ & & & & & \\
\hline Female & 469 & $48.09 \%$ & $35.54 \%$ & & & & & \\
\hline Age & & & & 11.861 & 0.001 & & 0.046 & 0.831 \\
\hline$<60$ & 790 & 41.59 & 36.01 & & & $0.973(0.758-1.250)$ & & \\
\hline$\geq 60$ & 806 & 51.03 & 29.07 & & & 1 & & \\
\hline Tumor size & & & & 72.465 & $<0.001$ & & 8.009 & 0.005 \\
\hline$\leq 5 \mathrm{~cm}$ & 674 & 59.91 & 43.53 & & & $0.811(0.702-0.938)$ & & \\
\hline$>5 \mathrm{~cm}$ & 922 & 36.58 & 24.52 & & & 1 & & \\
\hline Tumor location & & & & 29.829 & $<0.001$ & & 1.19 & 0.257 \\
\hline Upper \& Diffuse & 759 & 38.89 & 25.81 & & & $0.917(.785-1.072)$ & & \\
\hline Middle \& Lower & 837 & 51.94 & 38.24 & & & 1 & & \\
\hline Histologic type & & & & 14.135 & $<0.001$ & & 1.876 & 0.171 \\
\hline Differentiated type & 861 & 43.63 & 29.12 & & & $1.107(.957-1.282)$ & & \\
\hline Undifferentiated type & 735 & 50.45 & 36.19 & & & 1 & & \\
\hline Depth of tumor invasion & & & & 151.942 & $<0.001$ & & 10.532 & 0.032 \\
\hline $\mathrm{T} 1$ & 43 & 97.46 & 90.62 & & & $0.199(0.055-0.717)$ & 6.098 & 0.014 \\
\hline $\mathrm{T} 2$ & 156 & 73.96 & 65.5 & & & $0.640(0.375-1.090)$ & 2.698 & 0.1 \\
\hline $\mathrm{T} 3$ & 103 & 64.92 & 45.31 & & & $0.615(0.418-0.905)$ & 6.073 & 0.014 \\
\hline $\mathrm{T} 4 \mathrm{a}$ & 1167 & 45.97 & 27.36 & & & $0.843(0.671-1.059)$ & 2.142 & 0.143 \\
\hline $\mathrm{T} 4 \mathrm{~b}$ & 127 & 21.95 & 10.19 & & & 1 & & \\
\hline
\end{tabular}


Table 3. Univariate and Multivariate Prognostic Analysis of Gastric Cancers (continued)

\begin{tabular}{|c|c|c|c|c|c|c|c|c|}
\hline \multirow[t]{2}{*}{ Factors } & \multirow[t]{2}{*}{$\mathrm{n}$} & \multicolumn{4}{|c|}{ Univariate analysis } & \multicolumn{3}{|c|}{ Multivariate analysis } \\
\hline & & 3-YSR & 5-YSR & $\mathrm{x}^{2}$ & $P$ & HR & $\mathrm{x}^{2}$ & $P$ \\
\hline node metastasis & & & & 290.327 & $<0.001$ & & 43.075 & $<0.001$ \\
\hline No & 560 & 70.71 & 54.08 & & & $0.511(0.334-0.784)$ & 9.485 & 0.002 \\
\hline N1 & 317 & 45.85 & 34 & & & $0.541(0.444-0.659)$ & 37.479 & $<0.001$ \\
\hline N2 & 345 & 37.19 & 22.16 & & & $0.655(0.549-0.782)$ & 21.968 & $<0.001$ \\
\hline N3 & 374 & 18.5 & 8.43 & & & 1 & & \\
\hline Distant metastasis & & & & 137.566 & $<0.001$ & & 1.217 & 0.272 \\
\hline M0 & 1508 & 48.36 & 34.46 & & & $0.756(0.460-1.243)$ & & \\
\hline M1 & 88 & 11 & 1.23 & & & 1 & & \\
\hline TNM stage & & & & 330.023 & $<0.001$ & & 34.735 & $<0.001$ \\
\hline I & 136 & 91.06 & 81.43 & & & $0.178(0.072-0.439)$ & 14.064 & $<0.001$ \\
\hline II & 465 & 65.73 & 46.93 & & & $0.341(0.209-0.556)$ & 18.516 & $<0.001$ \\
\hline III & 907 & 33.47 & 21.17 & & & $0.505(0.396-0.644)$ & 30.438 & $<0.001$ \\
\hline IV & 88 & 11 & 1.23 & & & & 1 & \\
\hline PLT count & & & & 14.423 & 0.006 & $0.808(0.706-0.925)$ & 9.556 & 0.002 \\
\hline Control group & 1476 & 48.17 & 32.21 & & & & & \\
\hline Thrombocytosis group & 120 & 32.24 & 22.62 & & & & & \\
\hline
\end{tabular}

In multivariate analysis tumor size $(p=0.005)$, invasion depth $(p=0.032)$, lymph node metastasis $(p<0.001)$, TNM stage $(p<0.001)$ and the platelet count $(p=0.002)$ were independent prognostic factor. The HR of thrombocytosis in prognosis of gastric cancer patients was 0.808 (0.7060.925).

\section{Discussion}

Elevation of blood platelet count is commonly observed in malignancy diseases. In our study, the mean level of platelet counts was $253.23 \pm 88.47 \times 1000 / \mu \mathrm{L}$, and $7.5 \%$ of gastric cancer patients had thrombocytosis, which was coincident with previous literatures (Aliustaoglu et al., 2010; Heras et al., 2010). Although the mechanism responsible for the elevated levels of serum IL- 6 and TPO in cancer patients remains vague, it had been confirmed that the significantly higher frequency of elevated IL-6 levels (Kabir and Daar, 1995) and up-regulation of TPO (McConnell et al., 2007) were observed in patients with malignancies in many reports. Meanwhile, cancer cells can release vascular endothelial growth factor (VEGF), which activates the coagulation cascade, resulting in platelets to be activated (Kuenen et al., 2002; Roselli et al., 2003). Activated platelets also secrete TPO further, which stimulates bone marrow to generate new platelets. Thus, platelets and cancer cells make up a positive feedback cascade in which each stimulates the other, potentiating the effect (Folman et al., 2000).

This study demonstrated the palate count was correlated with clinical features, which was in line with previous study (Aliustaoglu et al., 2010; Aminian et al., 2011). Thrombocytosis was also found more frequently in patients with advanced stage and a higher histological grade, which also can be investigated in colorectal cancer (Sasaki et al., 2012) and nasopharyngeal carcinoma (Gao et al., 2013) etc.

Platelets synthesize and transport several angiogenic factors such as VEGF, platelet derived growth factor (PDGF), basic fibroblastic growth factor (bFGF), epidermal growth factor (EGF), and matrix metalloproteinases (MMP), which are known as stimulators of tumor angiogenesis (Buergy et al., 2012; Wang et al., 2011). Mohle et al showed that platelets adhere to the tumorrelated endothelium and release high concentrations of VEGF. Thus, the formation of the microvascular arrest of tumor cells at distant sites was facilitated (Mohle et al., 1997). Various experimental models have established the crucial steps on different molecular levels that underlie the pro-metastatic function of platelet-tumor cell aggregates within the microenvironment of tumor.

In addition, Labelle et al., recently demonstrated in their experimental lung metastasis model that plateletderived TGF- $\beta / \mathrm{Smad}$ and NF-Kb pathway are critical steps in which circulating tumor cells undergo epithelialmesenchymal transition (EMT) to acquire invasive and metastatic phenotypes, and ultimately colonize distant organs (Labelle et al., 2011).

In a number of cancers, lymphatic metastasis was found to be a common pattern of tumor cells after drop out from the primary tumor. In our study, the higher platelet counts and thrombocytosis was associated with lymph node metastasis. Previous researches suggested that platelets were important in the development of lymphatic vessels (Bertozzi et al., 2010; Liu et al., 2013; Suh et al., 2012). Bertozzi et al found that platelets and podoplanin function in the developmental separation of blood and lymphatic circulation in the embryo. Also, lymph-angiogenic factors such as VEGF, PDGF, and $\beta$ FGF can be synthesized and transported by platelets into the blood circulation and tissues, these factors were able to improve the development of lymphatic vessels (Bertozzi et al., 2010).

What's more, activated platelet-tumor cell aggregates in the circulation facilitate immune evasion of tumor cells. Platelets facilitate cohesion of tumor cells and leukocytes to form hetero-aggregates, which adhere to vascular endothelial cells and act as physiologically protecting tumor cells against NK cell-mediated lysis and shear stress (Cho et al., 2012; Gupta and Massague, 2004).

Owing to above mechanisms, aberrant activation of platelets and coagulation pathway is associated with poorer prognosis in many tumors (Aminian et al., 2011; Sasaki et al., 2012). In Kawai et al's study, thrombocytosis 
before pre-operative chemoradiotherapy predicts poor response and shorter local recurrence-free survival in rectal cancer (Kawai et al., 2012). Consistently, in our study, we clearly demonstrated that thrombocytosis is an independent factor of survival.

Due to the presence of thrombocytosis in some solid tumors has been associated with poor prognosis, there is increasing interest in the potential role of antithrombotic agents in the treatment of cancer patients. Several literature have showed that anticoagulants significantly improved survival in cancer patients. Nevertheless, clinical studies have been limited and have reported some controversial conclusions. A meta analysis of 11 studies demonstrated a significant reduction in overall mortality with anticoagulant therapy in cancer patients (Kuderer et al., 2007). Phillips et al. have demonstrated that low molecular weight heparin application significantly increases tumor chemo-responsiveness (Phillips et al., 2011). However, Van Doormaal et al did a multicenter, randomized and open-label trial in patients with advanced malignancy, nadroparin had no effect on time to disease progression (van Doormaal et al., 2011). These studies suggested the complicated and manifold molecular mechanisms in cancer-platelet interactions (Rebuffat et al., 2010). Large scale multi-center prospective clinical trials were called for confirming the mechanisms and effect of anticoagulants treatment in cancer therapy before the antithrombotic treatment applied in clinical therapy of cancer.

\section{Acknowledgements}

This work was supported partially by the Tianjin Natural Science Funds (No. 13JCYBJC24200) and National Natural Science Fund (81302250) of China.

\section{References}

Aliustaoglu M, Bilici A, Ustaalioglu BB, Konya V, Gucun M, et al (2010). The effect of peripheral blood values on prognosis of patients with locally advanced gastric cancer before treatment. Med Oncol, 27, 1060-65.

Aminian A, Karimian F, Mirsharifi R, et al (2011). Significance of platelet count in esophageal carcinomas. Saudi $J$ Gastroenterol, 17, 134-7.

Bertozzi CC, Hess PR, Kahn ML (2010). Platelets: covert regulators of lymphatic development. Arterioscler Thromb Vasc Biol, 30, 2368-71.

Buergy D, Wenz F, Groden C, Brockmann MA (2012). Tumorplatelet interaction in solid tumors. Int J Cancer, 130, 2747-60.

Cho DS, Kim SJ, Lee SH, et al (2011). Prognostic significance of preoperative C-reactive protein elevation and thrombocytosis in patients with non-metastatic renal cell carcinoma. Korean J Urol, 52, 104-9.

Cho MS, Bottsford-Miller J, Vasquez HG, et al (2012). Platelets increase the proliferation of ovarian cancer cells. Blood, 120, 4869-72.

Choe KS, Correa D, Jani AB, Liauw SL (2010). The use of anticoagulants improves biochemical control of localized prostate cancer treated with radiotherapy. Cancer, 116, $1820-6$.

Folman CC, Linthorst GE, van Mourik J, et al (2000). Platelets release thrombopoietin (Tpo) upon activation: another regulatory loop in thrombocytopoiesis? Thromb Haemost, 83, 923-30.

Gao J, Zhang HY, Xia YF (2013). Increased platelet count is an indicator of metastasis in patients with nasopharyngeal carcinoma. Tumour Biol, 34, 39-45.

Greene FL, Sobin LH (2009). A worldwide approach to the TNM staging system: collaborative efforts of the AJCC and UICC. J Surg Oncol, 99, 269-72.

Gupta GP, Massague J (2004). Platelets and metastasis revisited: a novel fatty link. J Clin Invest, 14, 1691-3.

Heras P, Hatzopoulos A, Kritikos N, Kritikos K (2010). Platelet count and tumor progression in gastric cancer patients. Scand $J$ Gastroenterol, 45, 1005-6.

Hwang SG, Kim KM, Cheong JH, et al (2012). Impact of pretreatment thrombocytosis on blood-borne metastasis and prognosis of gastric cancer. Eur J Surg Oncol, 38, 562-7.

Ikeda M, Furukawa H, Imamura H, et al (2002). Poor prognosis associated with thrombocytosis in patients with gastric cancer. Ann Surg Oncol, 9, 287-91.

Jemal A, Bray F, Center MM, et al (2011). Global cancer statistics. CA Cancer J Clin, 61, 69-90.

Kabir S, Daar GA (1995). Serum levels of interleukin-1, interleukin-6 and tumour necrosis factor-alpha in patients with gastric carcinoma. Cancer Lett, 95, 207-12.

Kawai K, Kitayama J, Tsuno NH, Sunami E, Watanabe T (2012). Thrombocytosis before pre-operative chemoradiotherapy predicts poor response and shorter local recurrence-free survival in rectal cancer. Int J Colorectal Dis, 28, 527-35.

Kuderer NM, Khorana AA, Lyman GH, Francis CW (2007). A meta-analysis and systematic review of the efficacy and safety of anticoagulants as cancer treatment: impact on survival and bleeding complications. Cancer, 110, 1149-61.

Kuenen BC, Levi M, Meijers JC, et al (2002). Analysis of coagulation cascade and endothelial cell activation during inhibition of vascular endothelial growth factor/vascular endothelial growth factor receptor pathway in cancer patients. Arterioscler Thromb Vasc Biol, 22, 1500-5.

Labelle M, Begum S, Hynes RO (2011). Direct signaling between platelets and cancer cells induces an epithelialmesenchymal-like transition and promotes metastasis. Cancer Cell, 20, 576-90.

Lee M, Kim SW, Nam EJ, et al (2011). The impact of pretreatment thrombocytosis and persistent thrombocytosis after adjuvant chemotherapy in patients with advanced epithelial ovarian cancer. Gynecol Oncol, 122, 238-41.

Li F, Zhang R, Liang H, Liu H, Quan J (2012). The pattern and risk factors of recurrence of proximal gastric cancer after curative resection. J Surg Oncol, 107, 130-5.

Liu HB, Gu XL, Ma XQ, et al (2013). Preoperative platelet count in predicting lymph node metastasis and prognosis in patients with non-small cell lung cancer. Neoplasma, 60, 203-8.

McConnell RJ, Brenner AV, Oliynyk VA, et al (2007). Factors associated with elevated serum concentrations of anti-TPO antibodies in subjects with and without diffuse goitre. Results from the Ukrainian-American Cohort Study of thyroid cancer and other thyroid diseases following the Chornobyl accident. Clin Endocrinol (Oxf), 67, 879-90.

Mohle R, Green D, Moore MA, Nachman RL, Rafii S (1997). Constitutive production and thrombin-induced release of vascular endothelial growth factor by human megakaryocytes and platelets. Proc Natl Acad Sci USA, 94, 663-8.

Naschitz JE, Yeshurun D, Eldar S, Lev LM. 1996. Diagnosis of cancer-associated vascular disorders. Cancer, 77, 1759-67.

Phillips PG, Yalcin M, Cui H, et al (2011). Increased tumor uptake of chemotherapeutics and improved chemoresponse 
by novel non-anticoagulant low molecular weight heparin. Anticancer Res, 31, 411-9.

Rebuffat SA, Morin M, Nguyen B, et al (2010). Human recombinant anti-thyroperoxidase autoantibodies: in vitro cytotoxic activity on papillary thyroid cancer expressing TPO. Br J Cancer, 102, 852-61.

Roselli M, Mineo TC, Basili S, et al (2003). Vascular endothelial growth factor (VEGF-A) plasma levels in non-small cell lung cancer: relationship with coagulation and platelet activation markers. Thromb Haemost, 89, 177-84.

Sasaki K, Kawai K, Tsuno NH, Sunami E, Kitayama J (2012). Impact of preoperative thrombocytosis on the survival of patients with primary colorectal cancer. World J Surg, 36, 192-200.

Sierko E, Wojtukiewicz MZ (2004). Platelets and angiogenesis in malignancy. Semin Thromb Hemost, 30, 95-108.

Suh DH, Kim HS, Chung HH, et al (2012). Pre-operative systemic inflammatory response markers in predicting lymph node metastasis in endometrioid endometrial adenocarcinoma. Eur J Obstet Gynecol Reprod Biol, 162, 206-10.

Unal D, Eroglu C, Kurtul N, Oguz A, Tasdemir A (2013). Are neutrophil/lymphocyte and platelet/lymphocyte rates in patients with non-small cell lung cancer associated with treatment response and prognosis? Asian Pac J Cancer Prev, 14, 5237-42.

van Doormaal FF, Di Nisio M, Otten HM, et al (2011). Randomized trial of the effect of the low molecular weight heparin nadroparin on survival in patients with cancer. $J$ Clin Oncol, 29, 2071-6.

Wang Y, Hu C, Dong R, Huang X, Qiu H (2011). Plateletderived growth factor-D promotes ovarian cancer invasion by regulating matrix metalloproteinases 2 and 9. Asian Pac J Cancer Prev, 12, 3367-70. 